\title{
ReseñA: Lo Abierto. El Hombre y el Animal'
}

\section{Por: Edisson Eduardo Rincón Higuera}

La obra, en su conjunto, es un desafío vital al pensamiento filosófico occidental, alimentado por un intenso propósito de transformación de las categorías comunes del pensamiento político tradicional. Se trata, en suma, de un ejercicio de comprensión filosófica que pretende, desde su propia negatividad, hacer una "profundización inaudita del misterio práctico-político de la separación".

El misterio al que aquí nos referimos es el de la separación entre lo animal y lo humano. Sobre ese eje se entretejerán las tres grandes fuentes que Agamben interpreta y comprende histórico-políticamente a lo largo de las veinte secciones en las que está dividida la obra: Koyève en discusión con Bataille, Heidegger, y porúltimo, Benjamín.

La lectura que Agamben realiza pretende, entonces, provocar un cambio radical en la categoría de lo humano y de lo animal, valiéndose de la acepción heideggeriana de lo abierto como constitución fundamental del Dasein en tanto aperiente y como proyecto. Sin embargo, repensar esa categoría heideggeriana traerá sorprendentes resultados para el propósito de comprender en qué momento y bajo qué condiciones se produce esa separación y cómo tal aclaración tiene importantes y esenciales consecuencias políticas, de manera tal que este problema "es más urgente que tomar decisiones sobre las grandes cuestiones, sobre los llamados valores y derechos humanos", pues no podríamos hablar de ello si ni siquiera se ha pensado sobre lo que significa ser humano, o aún más sobre la animalidad de lo humano. Lo que aquí se pone en juego es, básicamente, el concepto de vida y las repercusiones que su definición traerá para la naturaleza humana y animal y sus múltiples relaciones y articulaciones.

Agamben inicia la comprensión del problema refiriéndose al códice de una Biblia judía del siglo XIII, en el cual los últimos grabados allí representados, describen el escenario del banquete mesiánico de los justos en el último día. Se representa entonces, en tanto fin del códice, el fin de la historia de la humanidad, el día del banquete final en el que los justos coronados comerán las carnes de Behemot y del Leviatán, los animales de los orígenes. Sin embargo, el hecho que realmente es sorprendente y que obsesiona profundamente a Agamben es el hecho de que, debajo de las coronas puestas en los justos, se puedan entrever rostros animales, no semblantes humanos. Tal imagen nos permite pensar en una transfiguración de la naturaleza humana en el reino mesiánico, algo así como una reconciliación humana con su animalidad al final de la historia. De esta manera, se estrechan gravemente las relaciones entre lo humano y lo animal, deviniendo una identificación de lo humano con las potencias animales.

1. AGAMBEN, Giorgio. Lo Abierto. El hombre y el animal, traducido por Antonio Gimeno Cuspinera, Ed. Pre-textos, Valencia, 2005, 122 p.

2. Egresado del Programa de Estudios en Filosofía de Uniminuto. 
Nos encontramos, desde ya, con el primer problema fundamental del libro, el problema del fin de la historia y de la figura que lo humano y lo animal tomarán en dicho periodo post-histórico. Fin de la historia: momento de la consumación de la evolución, tránsito hacia lo humano finalizados, fin de la evolución. En ese sentido, Agamben, poniendo sobre el telón la lectura hegeliana de Koyève, plantea la problemática del final de la historia como la cesación del proceso dialéctico de negación que supone la evolución y la posibilidad de que, al final de la historia, desaparezca el hombre mismo, en tanto el sujeto se pone en juego en la negación que supone el trabajo dialéctico de la historia.

Los grabados gnósticos de esa representación, en la que también aparecen cuerpos humanos acéfalos, inquietan a Bataille y a Koyève, maestro del primero, y los hace posicionarse en lugares encontrados. Para el último, la desaparición de lo humano no es ninguna catástrofe, pues el mundo natural sigue su curso y en ese proceso lo humano permanece en la vida como animal; de esta manera desaparece la oposición entre sujeto y objeto, provocando, a su vez, la aniquilación del individuo libre e histórico, la cesación de la acción misma de ese individuo, y la desaparición total de la filosofía, pues ante el final del cambio evolutivo humano, ya no hay que cambiar los principios de conocimiento del mundo y de sí mismo. Con ello Koyève plantea entonces el fin de la historia, el fin del individuo y el fin de la filosofía; sin embargo, proclama que el arte, el amor y el juego se mantienen, pues ellos hacen feliz al hombre, ese es el 'resto' que sobrevive a la muerte del hombre.

Para Bataille, el conflicto radica en pensar que ese 'resto' que sobrevive se convierta en una función animal: Bataille no tolera que tales experiencias pasen a ser parte de la praxis animal, lo cual traería consigo una animalización del arte, el amory el juego, con lo que los hombres post-históricos tendrían que construir, amar y jugar, justo como lo hace un animal. Frente a esa funesta posibilidad, Bataille plantea la posibilidad de que exista una 'negatividad sin empleo', esto es, una negatividad en la que ya no exista la acción, una vida como 'herida abierta', un 'resto' negativo que para Bataille se trata del erotismo, la risa y el júbilo ante la muerte: ya no hay cabezas de animales, sino acéfalos.

Bajo estas dos posiciones se vislumbra el problema del devenir animal del hombre al final de la historia. Tal problema tiene su reflejo en el contexto de la segunda guerra mundial, momento que parece coincidir con las afirmaciones de Koyève: los hombres pasan a ser animales, resignados y mansos como ovejas, humillados sustraídos de su humanidad. Koyève repiensa la problemática luego de la muerte de Bataille y se enmarca en el problema de la felicidad del hombre en la post-historia. La lectura que Agamben realiza de este punto es una clara alusión al problema del musulmán como desecho del judío luego de los campos de concentración: de su felicidad si los caracterizamos como animales post-históricos, dejando entrever, entonces, el trasfondo político que guarda el tratamiento de la problemática hasta ahora suscitada.

Koyève afirma ahora que no es posible pensar en la felicidad humana en la posthistoria, pues con su fin, el arte, el juego y el amor también deben devenir naturales, porlo que éstos no estarán felices sino contentos. Fin del hombre, aniquilación del lenguaje humano, fin de la sabiduría, fin de la filosofía, amor a la sabiduría. La lectura del final de la historia que hace Koyève no es una profecía, es un hecho ya consumando: el fin de la historia ya sucedió en la batalla de Jena en 1806, cuando la razón alcanzó su punto máximo y se tiranizó en la figura napoleónica al invadir Berlín. La batalla de Jena, para Koyève, es el punto en el que termina la 
evolución histórica del hombre, lo que viene después, será el reflejo de la alineación y de la animalización de lo humano.

El género de vida paradigmático de la posthistoria es el American way of life, al cual, Koyève le contrapone la sociedad japonesa, y la postula como una sociedad post-histórica que no dejó de ser humana, pues tomo una vía distinta a la American way. Sin embargo, ¿̇cómo pensar que los japoneses hayan tenido algo como historia si su religión, su moral y su política no son occidentales, y por ello, no son históricas? El punto radica en la vaciedad de valores con la que son capaces de vivir los japoneses, postulándose así un proceso de esnobismo que provoca, entonces, la 'japonización de los occidentales', por lo que la post-historia japonizada será humana. Con ello, Koyève cambia su postura radical y propone su nueva tesis, según la cual, el hombre sobrevive a la historia en forma de esnobismo japonés, algo así como una 'negatividad sin empleo' a la que se refería el propio Bataille. En este punto, entonces, el esnobismo japonés es la figura post-histórica de lo humano. Sin embargo, eso intensifica aún más la tensión entre la animalidad y la humanidad, pues el hombre que sobrevive en esa franja ultrahistórica se muestra indefinido y atravesado por cesuras ineludibles, entablándose una relación entre el esnob japonés, el rostro animal y el acéfalo.

Sin embargo, hay algo que para Agamben no queda muy claro en su lectura de Koyève: éste no tiene en cuenta la transformación del estado moderno en un biopoder, en el cual se empieza a asumir el cuidado de su propia vida animal y natural. Con ello nos enfrascamos en el segundo gran problema que atraviesa el texto: el concepto de vida y su relación con el biopoder. Y la problemática se muestra en la indefinibilidad e inasibilidad del concepto de vida que, por el contrario, parece estar cada vez más dividido e inalcanzable. En ese ejercicio filosófico de distinción, especialmente aristotélico dice Agamben, se ha conseguido distinguir entre la vida orgánica y la vida animal, siendo la primera una sucesión habitual de funciones sin conciencia. En ese sentido, en el hombre cohabitan, sin coincidir, estos dos modos de vida, por lo que la vida orgánica se da antes de la vida animal que en la muerte deviene nuevamente orgánica.

Esa nuda vida, que es la vida orgánica, viene a ser un factor importante en la zona de cuidado del biopoder y la biopolítica, como tarea esencial y suprema, el cuidado de la vida de la población, aun en su indefinibilidad. Sin embargo, sigue la pregunta pendiente que se esconde a lo largo del texto żqué hace que lo humano se separe de lo animal? pues esto es ineludible a la hora de replantear el humanismo y las cuestiones políticas que a tal definición le competen.

En este punto, Agamben plantea uno de los desafíos de su comprensión: dejar de pensar en el hombre tradicional como articulación cuerpo-alma, animal-social, viviente-logos, y pensarlo, por el contrario, como el resultado, como el 'resto' de la desconexión profunda de esos elementos, de allí que no se piense el 'misterio metafísico de la conjunción', sino el 'misterio prácticopolítico de la separación' como referíamos al inicio. La conciencia de esa constante división, de esa permanente cesura resultado de la fragmentación del sujeto y de la pérdida de la yoicidad ilustrada, nos guiará a la hora de comprender al hombre separado del nohombre y a lo animal separado de lo humano, que es, en el fondo, la problemática fundamental sobre la que gira el texto.

En vista de tal propósito, Agamben hace un irónico seguimiento a las doctrinas de los teólogos medievales sobre la fisiología de los bienaventurados y la doctrina de Tomás de 
Aquino, quien afirma que la vida mesiánica es una vida contemplativa en el que no hay lugar para los animales. Excluida la vida animal del paraíso, se encuentra amenazado el umbral que separa lo humano de lo animal, esa frontera aún sigue siendo indefinida, lo humano no podría sobreponerse a lo animal pues no sería tal, además, afirma Agamben, tal doctrina entra en contradicción con el mito edénico de la convivencia con los animales, por lo que "el paraíso siembra la duda sobre el edén".

Frente a tales 'experimentos mentales' medievales, Agamben sienta la posición del fundador de la taxonomía científica moderna, Linneo, quien recurriendo a una investigación puramente naturalista y que se concentra únicamente en el cuerpo y no en un plano moral y religioso, plantea la figura del homo sapiens, a la hora de definir la frontera entre lo animal y lo humano. Agamben tiene en cuenta el hecho de que para el siglo XVIII dichas fronteras eran profundamente inciertas, tanto que algunos animales mitológicos y las sirenas estaban incluidos en los tratados de animales de la época sin ningún tipo de sorpresa. Sin embargo, haciendo un lúcido análisis del significado del homo sapiens, Agamben se da cuenta que éste se muestra como un artificio de reconocimiento humano, es decir, un dispositivo por medio del cual, el hombre se hace humano sólo mediante el reconocimiento de sí mismo, atendiendo a esa dialéctica negativa de la evolución en la que lo humano se pone sobre lo animal negándole gracias a tal artificio. Sin embargo, tal ejercicio supone primero un reconocimiento en el simio para, desde allí, elevarse por encima de él, de manera que es sólo si se reconoce como no ser.

A tal artificio, Agamben lo denomina máquina antropológica, y la postula como un dispositivo irónico que permite entrever la carencia de una naturaleza propia de lo humano, mostrándose así como un intersticio sin rostro, sin dignidad, como un sin-rango, provocando que lo humano devenga labilidad e inhumanidad dada su carencia de esencia específica. Agamben delata con ello la precariedad de lo humano. Pero el espectro problemático de esa máquina antropológica va más allá de la producción de lo humano por medio de la oposición hombre/animal: Agamben afirma que existe una máquina antropológica moderna que produce el nohombre por medio de la oposición humano/inhumano, logrando que se excluya como no-humano algo que era humano: la figura del judío, el no-hombre producto del hombre, el 'ultracomatoso'. Ese es el tercer gran problema del texto, y podría decirse, el aporte interpretativo en general de Agamben en la obra: el problema metafísico-político de la producción del no-hombre fruto de la máquina antropológica moderna: animalización de lo humano, creación del extranjero en un estado de excepción, en una zona gris-vacía que, en tanto abismal cesura, no produce vida animal ni vida humana, sino la nuda vida, para Agamben, la figura extrema de lo humano y lo inhumano.

Definida ahora la vida como nuda vida gracias a la maquina antropológica moderna en la post-historia, Agamben procede a continuación a realizar una análisis comprensivo de la posición heideggeriana del mundo, enriqueciendo con ello las razones para tomar una posición frente a la frontera entre lo animal y lo humano, ayudados ahora por la concepción de lo abierto concretamente. Para Agamben, Heidegger es el filósofo del siglo XX que más se esforzó por separar al hombre del viviente, ello gracias a su concepción de lo abierto, de mundo y tierra sobre la que insistirá más adelante.

Heidegger es influenciado profundamente por el zoólogo Jacob von Uexküll quien, 
haciendo frente a la ciencia clásica que concebía un mundo único jerarquizado, propone una infinita variedad de mundos perceptivos vinculados entre sí como una partitura musical, por lo que las relaciones, por ejemplo, entre un sujeto animal con su ambiente no tienen el mismo espacio-tiempo del mundo humano. En ese sentido, se hace la distinción entre Umgebung como espacio objetivo en el que vemos moverse a un ser vivo y el Umwelt como el medio ambiente dotado de elementos portadores de significado, y que se muestra como unidad autocontenida, por lo que la tarea del investigador natural sería reconocer los portadores de significado del medio ambiente animal. Con ello, Heidegger, modifica la relación entre el viviente y el Umwetl proponiendo el ser-en-el-mundo como estructura humana fundamental.

Se modifica la relación cuando Heidegger se refiere a la relación del animal con el mundo como pobreza de mundo, y al hombre como formador de mundo, rechazando radicalmente la concepción clásica del hombre como animal racional. En ese sentido, la vida, problema que atraviesa el texto entero, sólo es accesible al ser-ahí, en tanto formador de mundo, modo de ser aperiente.

En el análisis de la caracterización que Heidegger hace de lo animal y lo humano, Agamben hace énfasis en el modo de ser del animal que éste describe: el aturdimiento, como un estar atrapado y absorto en su medio ambiente, es decir, un no actuar, pues el animal no tiene conducta, sólo se comporta. Por ello mismo, el animal se comporta en un medio ambiente, en tanto aturdido, nunca en un mundo. Sin embargo, el animal, al ser pobre de mundo, debe ser distinto a la piedra que es privada de mundo. Pobreza de mundo significa, entonces, que el animal no se encuentra en desvelabilidad del ente, que no es abierto, pero por ello tampoco es cerrado, sino que, más bien, en el aturdimiento se halla suspendido en un estar absorto y por ello está abierto en una no-relación con el ente que se le abre pero al que no puede acceder. Ello es, el animal es aperturidad sin desvelamiento, está obligado a prescindir de mundo: es un estar abierto con la condición de no relacionarse con ello.

Frente a ello, el mundo se da como desvelabilidad del ente en cuanto tal, y lo abierto es el nombre del ser en el mundo; se piensa entonces lo abierto como aletheia, es decir como sin-ocultamiento. Lo abierto como el desocultarse del ser que sólo puede ver el hombre, por medio de la palabra en cuanto develadora, en la inmersión del $c \circ n f l i c t o$ esencial ocultamiento/desocultamiento. De esta manera, el animal en tanto aturdido es incapaz de develar y se mantiene absorto en su propio medio ambiente (desinhibidor en términos heideggerianos), pero ello como modo propio de ser del animal, esto es, como conmoción esencial del mismo. El hombre, en tanto aperiente y proyecto, conforma mundo en la develabilidad del ente por medio de la palabra y de lo abierto. Es en este punto, donde aparentemente se separa el medio ambiente animal del mundo humano. Sin embargo, el análisis del aturdimiento animal, y ahora el análisis del aburrimiento profundo humano, nos llevarán a mirar cómo éstos siguen íntimamente cercanos.

Así pues, se entiende al aturdimiento animal y al aburrimiento profundo como tonalidades emotivas fundamentales, en tanto exposición sin develamiento. Y ello se ve en el aburrimiento profundo, si lo entendemos como operación esencial para alcanza la apertura de mundo. El aburrimiento profundo es, para Heidegger, el ser-dejado-en-el-vacío, en el que las cosas están ahí pero en total indiferencia, el ente que no desaparece pero no nos ofrece nada, y por la que el ser-ahí se encuentra entregado 
a ese ente que se le niega. Aburrimiento también, como un ser-mantenido-ensuspenso, es decir como la inactividad o la 'tierra fecunda sin cultivar' de la posibilidad en cuanto inutilizada, también, por la indiferencia del ente, ello es, negación misma de la posibilidad. Es en este punto, en el que el aburrimiento nos deja entrever, sorprendentemente, la proximidad entre el animal y el Dasein, pues ambos, en tanto aturdimiento y aburrimiento, están abiertos a un cierre, abierto a algo que se les niega obstinadamente. Pero en tanto el desactivar la posibilidad es la potenciación de la posibilidad misma, deviniendo un poder-ser, se da el paso de la pobreza de mundo al mundo y del ser vivo al Dasein, gracias a la suspensión, a través del aburrimiento, de la relación del viviente con el medio en la conformación de mundo, lo que comprueba la mención que hacía Agamben sobre el empeño de distinción heideggeriana entre viviente y Dasein.

Sin embargo, todo ello indica, subversivamente, que el ocultamiento reina en el corazón del desocultamiento, es decir lo nodesvelado del animal en lo abierto del Dasein, "la lucha intestina entre el hombre y el animal". El Dasein es, entonces, el animal que aburriéndose se despierta de su propio estarabsorto, de su propio aturdimiento.

En ese sentido, la relación hombre/animal deviene relación mundo/tierra, por lo que el hombre tiene mundo en tanto mora en lo abierto del ente, y la tierra se cierra en sí misma resistiéndose a la apertura en tanto absorto. Sin embargo, es necesario preservar el conflicto esencial, pues mundo/tierra no son separables, ya que el mundo se funda en la tierra y la tierra surge por medio del mundo e $n$ e s a di a lé ctica de ocultamiento/desocultamiento. Con ello la humanitas se mantiene abierto ante el cierre de la animalitas, llevando hacia lo abierto lo cerrado en sí mismo en una suspensión de lo que yace absorto.

Para Agamben, todo ello es aún una máquina antropológica, aquí se produce un Dasein por medio de la división entre mundo y tierra, reconociendo, todavía, la posibilidad de un destino histórico para un pueblo. Pero el mismo Heidegger reconoce luego el error de esa esperanza al pensar que "la existencia histórica de un pueblo se ha desvanecido". Así se le da cabida a la post-historia en el momento del ocaso de la metafísica. Es el momento del eclipse.

Todo el análisis que Agamben ha podido leer hasta ahora, lo lleva a afirmar que ya no existen grandes tareas históricas asumibles por los Estados. Y propone lo que será su gran tesis, que sólo podía comprenderse luego del recorrido que hemos hecho, pero que ya se venía prefigurando: la apuesta actual, ante tal panorama post-histórico eclipsado, es por el asumir como tarea la propia existencia, esto es, la existencia como nuda vida y la tarea de del cuidado de la propia vida biológica como la suprema tarea política. Nuda vida, esto es, una vida que ya no sabe reconocerse humana o animal, una vida que se cierra a su propia apertura.

De esta manera, en esta obra, Agamben hace una lectura comprensiva de la máquina antropológica de la filosofía occidental, permitiendo entrever las relaciones que se entretejen entre la animalidad y la humanidad, y la apuesta por un nuevo pensar que deje de articular lo animal y lo humano y se arriesgue a pensar una nuda vida, más allá de las articulaciones, y por el contrario, en la conciencia de la separación. Para ello, se sirve, finalmente, de una lectura de Benjamín, quien propone una imagen distinta de la relación naturaleza/hombre, dejando a un lado la maquina antropológica. En esa nueva imagen se configura una nueva dialéctica 
entre hombre y naturaleza en la que ninguna de las dos partes domina, sino que se funda un 'entre' entre los dos términos, con ello se suspende también la máquina antropológica que articulaba la naturaleza y el hombre para producir lo humano y lo inhumano.

Así, ese entre, que no es hombre ni animal se pone como 'noche salvada, hay un mutuo alejamiento del secreto y del misterio de la frontera entre el animal y el hombre, por lo que se accede a una nueva vida más allá del conocimiento y de la naturaleza: la ausencia del misterio que funda un secreto más íntimo, la manifestación de una naturaleza nueva, figura suprema de la vida, ociosidad, nuda vida, en tanto ya no es pura razón que domina la naturaleza, ni pura pobreza de mundo animal, sino un estado de agonía, de noconocimiento, una zona gris, una zona de ignoscensia, como el perdonar la ausencia de misterio, la serenidad de la nuda vida como el dejar-ser.

Por ello, la nuda vida, en tanto fuera del ser, es decir, más allá de la diferencia entre ser y ente, se dona como la posibilidad de desactivar e inutilizar la máquina antropológica, de aventurarse en el vacío de lo suspendido, de lo gris, el "shabbat del animal y del hombre", es decir, el desafío de pensar a un hombre post-histórico no con una animalidad reencontrada, sino como una figura gris que deja ser, un viviente sin tarea histórica, como decíamos al principio, la profundización en el misterio práctico-político de la separación, y de la nuda vida más allá de cualquier máquina antropológica articuladora, es en últimas la propuesta fundamental de Giorgio Agamben. 


\section{Libros $_{\text {Recomendados }}$}

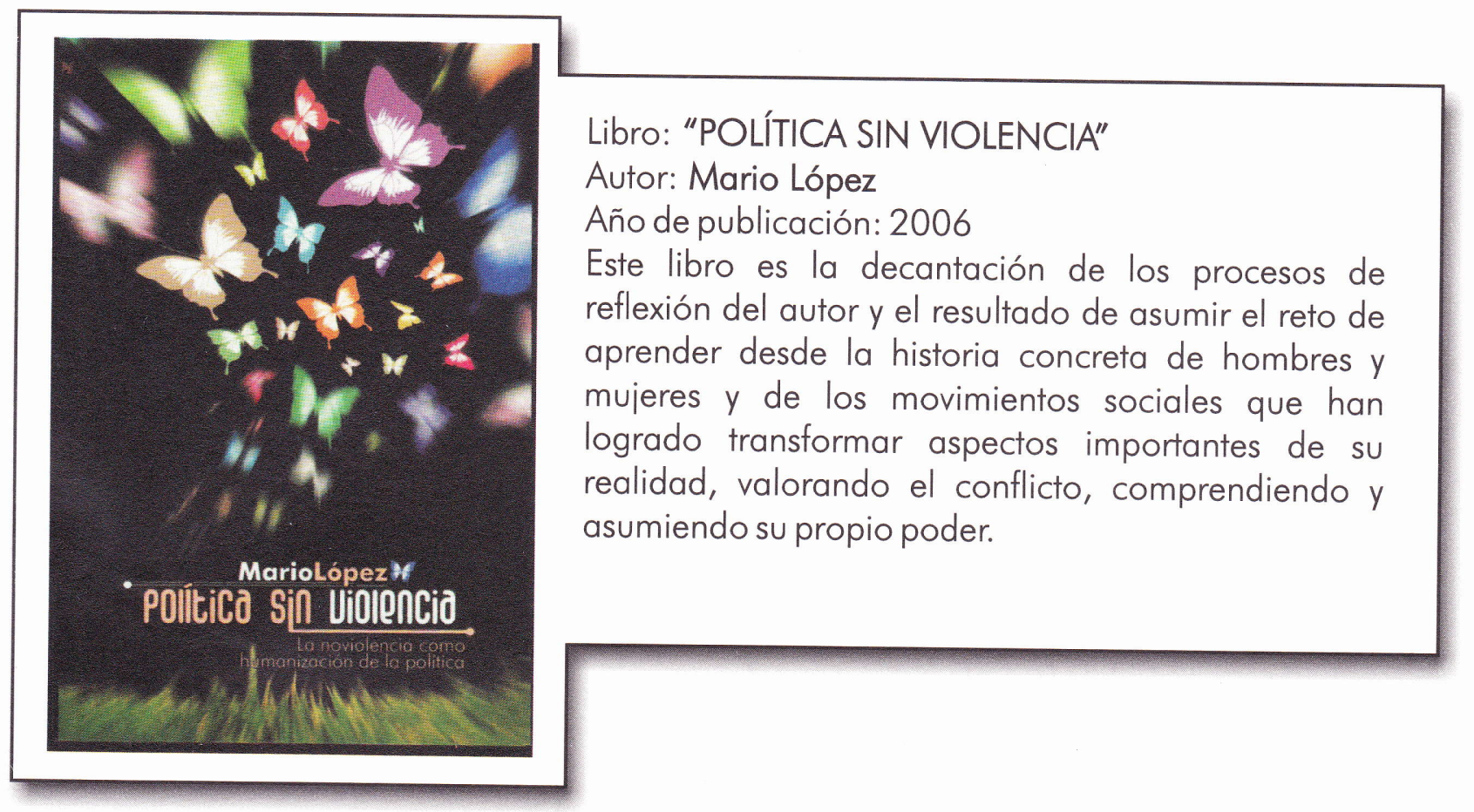

\section{Programas}

Recomendados

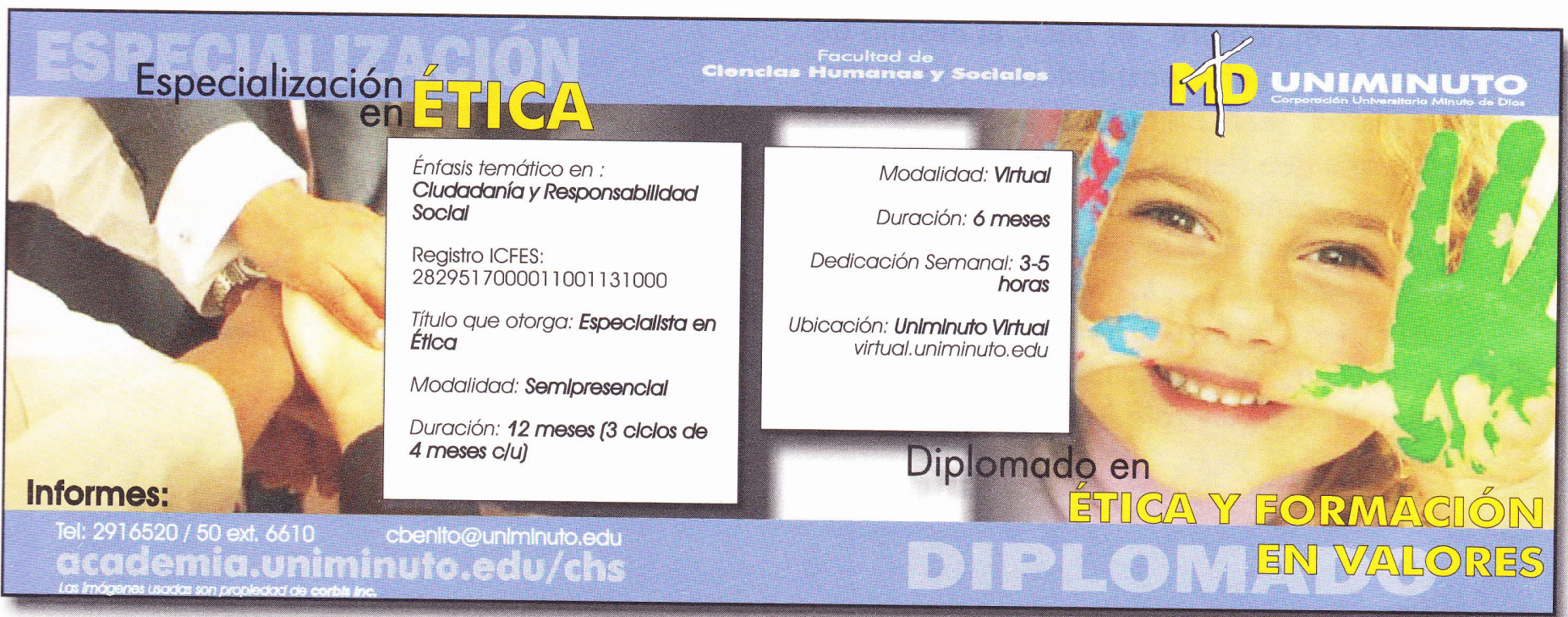




\section{Criterios de Publicación}

Polisemia es la revista de la Facultad de Ciencias Humanas y Sociales de UNIMINUTO y el Centro de Estudios e Investigaciones Humanas y Sociales (CEIHS). Contiene artículos integrados en cuatro secciones: "Pensamiento Social", "Reflexiones Filosóficas", "Caminos de Paz y Noviolencia" y "Avances \& Reseñas".

Polisemia se presenta como una revista para todo tipo de lectores interesados en los temas humanos y sociales, con el propósito de aportar un espacio de reflexión interdisciplinaria en torno a problemáticas sociales.

Los textos son escritos en su mayor parte por docentesinvestigadores de la Corporación Universitaria Minuto de Dios, además de habilitar espacios permanentes para dar cabida a textos de autores invitados a nivel nacional e internacional.

Cualquier lector puede realizar sus críticas o aportes, con la seguridad de que sus sugerencias serán estudiadas por el Consejo Editorial, o proponer artículos a la dirección electrónica: polisemia@uniminuto.edu El proceso de selección de artículos dependerá del concepto de lectores externos escogidos entre un grupo de pares académicos y de los procedimientos que establezca el Consejo Editorial para cada edición de la revista.

La extensión de los artículos debe mantenerse entre 10 y 20 páginas, incluyendo bibliografía, en formato Word, tamaño carta, en letra "Arial" de 11 puntos, interlineado sencillo. Los textos que se presenten deben ser originales, preferiblemente inéditos y considerados un aporte al conocimiento y reflexión en las áreas humanas y sociales.

Cada artículo debe contener: un título (en lo posible, breve), un resumen (de unas 10 líneas como máximo) en español y traducido al idioma inglés, tres o cuatro palabras claves relacionadas con el artículo, una breve referencia del currículo del, o los autores. En la pá $g$ i n a we b d e $\quad P$ o I i s e m i a (academia.uniminuto.edu/ceihs/polisemia/) se pueden encontrar las instrucciones y/o parámetros de presentación de artículos. 